\title{
Impact of an Extreme Typhoon Event on Subsequent Sediment Discharges and Rainfall-Driven Landslides in Affected Mountainous Regions of Taiwan
}

\author{
Ching Hung $\mathbb{D}^{1},{ }^{1}$ Guan-Wei Lin $\mathbb{D},{ }^{2}$ Hsien-Li Kuo, ${ }^{2}$ Jia-Ming Zhang, ${ }^{2}$ Chi-Wen Chen, ${ }^{3}$ \\ and Hongey Chen $^{3,4}$ \\ ${ }^{1}$ Department of Civil Engineering, National Cheng Kung University, No. 1, University Road, Tainan City 70101, Taiwan \\ ${ }^{2}$ Department of Earth Sciences, National Cheng Kung University, No. 1, University Road, Tainan City 70101, Taiwan \\ ${ }^{3}$ National Science and Technology Center for Disaster Reduction, No. 200, Sec. 3, Beixin Road, Xindian District, \\ New Taipei City, Taiwan \\ ${ }^{4}$ Department of Geosciences, National Taiwan University, No. 1, Section 4, Roosevelt Road, Taipei 10617, Taiwan
}

Correspondence should be addressed to Guan-Wei Lin; gwlin@mail.ncku.edu.tw

Received 20 April 2018; Revised 17 August 2018; Accepted 5 September 2018; Published 27 November 2018

Academic Editor: Marco Petitta

Copyright (c) 2018 Ching Hung et al. This is an open access article distributed under the Creative Commons Attribution License, which permits unrestricted use, distribution, and reproduction in any medium, provided the original work is properly cited.

\begin{abstract}
Fluctuations in the sediment yielding rate within mountainous areas are found after extreme precipitations. These changes are associated with rainfall-driven landslides and can be evaluated through observations of sediment transported in river water. In this study, we assess the differential impact level and duration of an extreme rainfall event caused by the 2009 Typhoon Morakot in Taiwan. Using a time series of suspended sediment data and landslide inventories within three affected catchments, our results found that the proportion of the typhoon-generated sediment discharges reached $58 \%$ of the 2009 annual sediment discharges, and the annual sediment discharges could be 15-fold higher than the average annual sediment discharges prior to the typhoon. The impact of the typhoon on suspended sediment discharge lasted for around four months. It is further revealed that a significant increase in the number of landslides was attributed to the impact of the extreme typhoon event, and the critical rainfall condition triggering landslides, based on the relationship between rainfall and landslide number and the rainfall intensity-duration thresholds, declined for $4-5$ years.
\end{abstract}

\section{Introduction}

Located in the subtropical monsoon climate area in Asia, Taiwan encounters an average of four typhoons annually and is subjected to an average rainfall of approximately $2500 \mathrm{~mm} / \mathrm{yr}$ [1]. In the wet seasons, such annual rainfall can induce numerous landslides in mountainous areas [2-4]. Because of generated landslides, fluctuations in the sediment yielding rate within mountainous areas can be perceived in Taiwan, especially after extreme precipitations given that sediments generated by landslides are largely transported to rivers [3, 5-10]. The above studies suggest that to better understand the role of extreme rainfalls on landslides and mitigate their social and environmental impacts, the issues associated with rainfall-driven landslides and sediment transported in river could be investigated.

In 2009, within a short period of six days (6-11 August), Typhoon Morakot dropped more than $1500 \mathrm{~mm}$ of rainfall in the central and southwestern mountainous regions of Taiwan (Figure 1(a)) [11], which resulted in catastrophic landslides and flooding disasters [12]. This extreme event caused more than 700 fatalities, destroyed hundreds of houses, and left thousands of people homeless. It is important to note that a large amount of soil and rock was delivered into the rivers along with heavy rains, producing large amounts of suspended sediment; therefore, this extreme rainfall event provides a good opportunity to evaluate the differential impact level and duration of affected areas that could be 


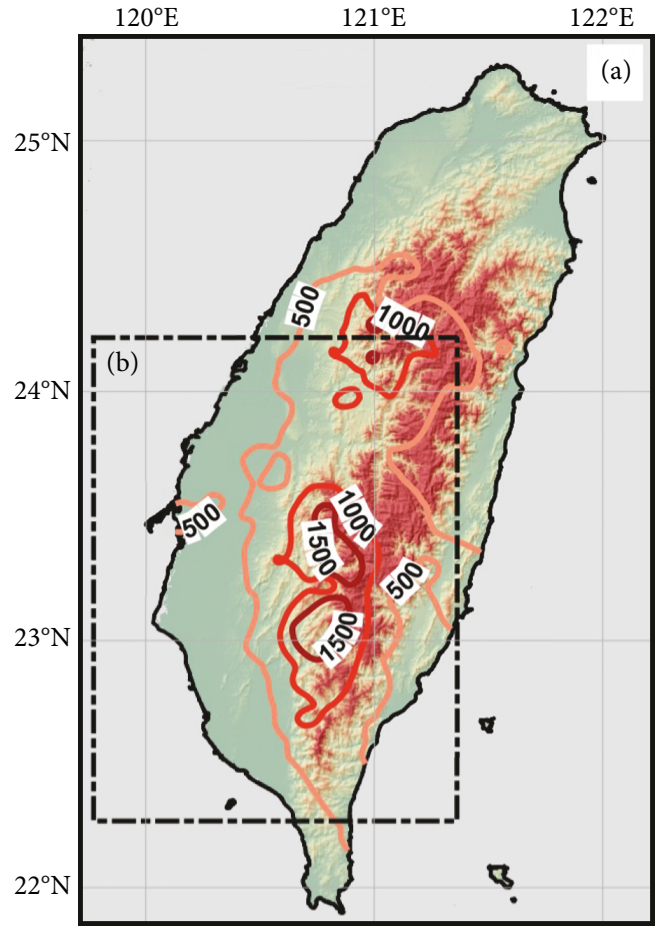

Rainfall contour (mm)

500

$-1000$

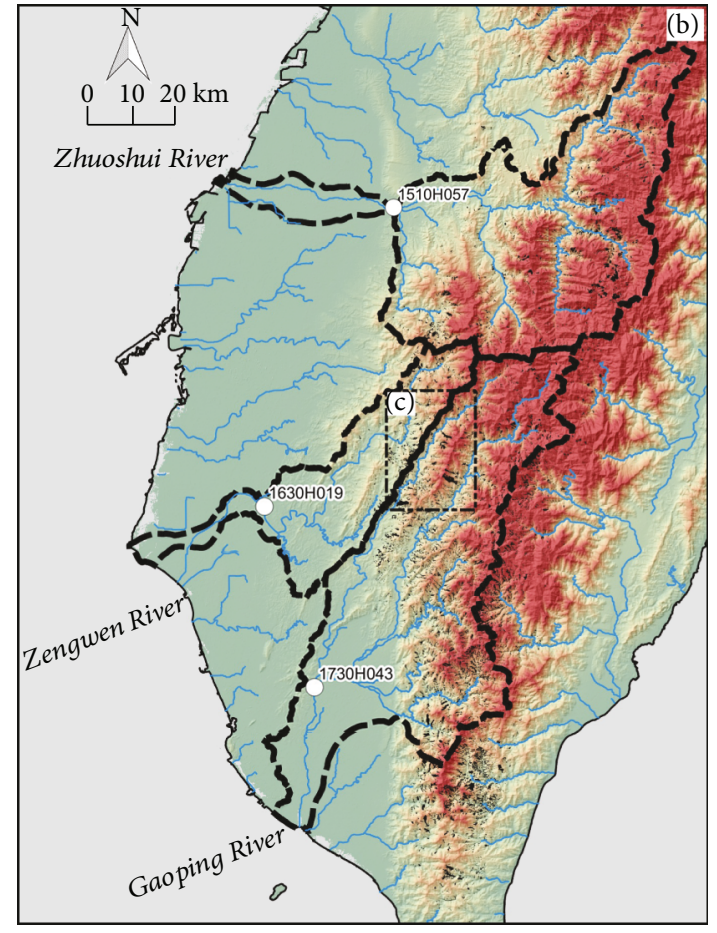

Hydrometric station

Elevation (m)

- River channel

Landslide

I Catchment boundary
- $0-499$

500-999

1000-1499

1500-1999

$>2000$

(a)

(b)

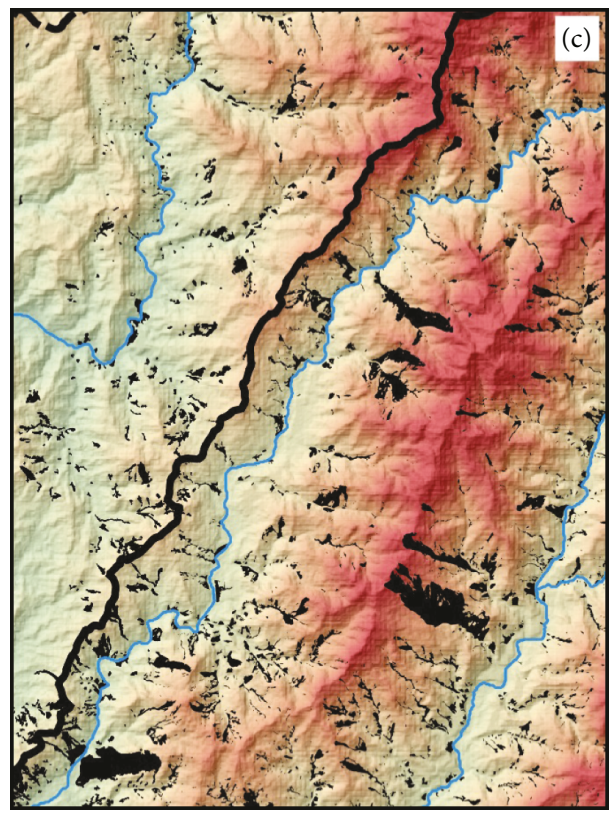

(c)

FIGURE 1: The rainfall and landslide distributions caused by Typhoon Morakot in 2009 and the 2009 annual suspended sediment discharges from the three rivers. (a) The contour lines represent the cumulative rainfall during the period from August 6 to 11, 2009. The numbers along the contour lines are the values of cumulative rainfall in $\mathrm{mm}$. (b) The location of hydrometric stations and the boundaries of the three rivers. (c) Zoom-in view of landslide distribution around the boundary between the Zengwen River and the Gaoping River. 
insightful for understanding the role of an extreme rainfall event on subsequent rainfall-driven landslides and sediment discharges.

In this study, we focused on the amount of suspended sediment discharge (SSD) and mapped landslides in three major river catchments in central and southwestern Taiwan, including the Zhuoshui River, the Zengwen River, and the Gaoping River, to assess the impact of an extreme rainfall event on the occurrence of rainfall-driven landslides and sediment discharges transported in rivers (Figure 1(b)). The total area of these three catchments is $7151 \mathrm{~km}^{2}$, covering the major regions affected by heavy rainfall during Typhoon Morakot. The Zhuoshui River is the longest river in Taiwan, with a total length of $187 \mathrm{~km}$ and a catchment area of $2906 \mathrm{~km}^{2}$. The Gaoping River, the second longest river in Taiwan, has a total length of $171 \mathrm{~km}$ and the largest catchment area in Taiwan, $3257 \mathrm{~km}^{2}$. The Zengwen River is the fourth longest river in Taiwan, with a main stream length of $139 \mathrm{~km}$ and a catchment area of $988 \mathrm{~km}^{2}$; furthermore, the largest reservoir in Taiwan is located in the upstream area of this river.

\section{Study Methods}

2.1. Estimating Suspended Sediment Discharge (SSD). The sediment concentration data used in this study were mainly collected from the Water Resources Agency (WRA) of Taiwan. The WRA staff sampled river water two to three times a month at each river hydrometric station using a DH-48 full-depth sampler and measured sediment concentrations [13]. The measured hydrometric data for this study were selected from the Changyun Bridge (1510H057) on the Zhuoshui River, the Xingchung Bridge (1630H019) on the Zengwen River, and the Liling Bridge (1730H043) on the Gaoping River. The rating curve method was used to estimate the amount of SSD transported during the whole year and during typhoon periods.

The rating curve method is one of the most common estimation methods for SSD [14-18], especially in cases of insufficient hydrometric data. The method is based on a power law regression relationship between the measured water discharge $Q\left(\mathrm{~m}^{3} / \mathrm{s}\right)$ and the daily suspended sediment discharge $Q_{s}(\mathrm{t})$. Furthermore, a $Q-Q_{s}$ equation can be used to estimate the amount of SSD through the measured water discharge (Figure 2). The $Q-Q_{s}$ equation is usually written in the form of $Q_{s}=\kappa Q^{b}$, where $b$ is determined by the availability and mobilization of sediment and $\kappa$ is the suspended sediment discharge at a unit discharge. Therefore, the rating curve method has an advantage in that only a small amount of measured sediment concentration data is required to estimate SSD. In general, the traditional rating curve method is suitable for estimating SSD in rivers within a transportdominated environment [19], but its shortcomings are that the estimated SSD values are expected values and that there are residuals between the calculated and measured SSD values. Therefore, a modified rating curve method was developed by Kao et al. [17] to reduce the residuals. An error correction parameter used in the modified rating curve method is written as follows:

$$
\beta=\frac{\sum_{i=1}^{n}\left(Q_{s i}-\kappa Q_{i}^{b}\right)}{\sum_{i=1}^{n} \kappa Q_{i}^{b}},
$$

where $Q_{s i}$ is the $i$ th measured daily SSD (ton) and $Q_{i}$ is the $i$ th measured water discharge $\left(\mathrm{m}^{3} / \mathrm{sec}\right)$. In general, twenty to thirty SSD measurements and in situ measurements of daily water discharge are collected per year at each hydrometric station. Hence, a yearly modified rating curve can be written as follows:

$$
\widehat{Q}_{s j}=\kappa Q_{j}^{b}(1+\beta),
$$

where $\widehat{Q}_{s j}$ is the calculated daily SSD (tons/day) and $Q_{j}$ is the measured daily water discharge $\left(\mathrm{m}^{3} / \mathrm{sec}\right)$ on the $j$ th day. In the study, all yearly rating curves were demanded to have a coefficient of determination greater than 0.70 . Once a modified rating curve is constructed for a given year, the annual SSD can be calculated by the following equations:

$$
\begin{aligned}
& \mathrm{TSS}=\frac{365}{n} \sum_{j=1}^{n}\left(\widehat{Q}_{s j}\right) \text { for normal years, } \\
& \mathrm{TSS}=\frac{366}{n} \sum_{j=1}^{n}\left(\widehat{Q}_{s j}\right) \text { for leap years, }
\end{aligned}
$$

where TSS is the annual SSD (tons) and $n$ is the number of measured daily water discharge data. In addition, the number of measurements of daily water discharge per year at each hydrometric station should be greater than 200 to make sure that the estimation of TSS is statistically convincing.

In this study, the daily water discharges measured at the three hydrometric stations were used to calculate the daily SSD using the modified $Q-Q s$ rating curve method. During the typhoon periods, $\widehat{Q}_{s j}$ accumulates in amount. The $\kappa$ and $b$ of the yearly rating curves obtained from the $Q-Q s$ equation mentioned earlier and the measured data of the three rivers are summarized in Tables S1, S2, and S3.

Given the fact that the largest reservoir in Taiwan only affects a tributary of the Zengwen River and its influence area is less than $50 \%$ of the entire catchment, the reservoir may not play a significant role in the $Q-Q s$ relationships at the downstream channels. In addition, the rapid accumulation of bedload in the reservoir area is mostly associated with the coarse sediment transport in the Zengwen River, suggesting that the influence of dam on the SSD could be minimized if it is based on the fine-grained sediment transport (i.e., suspended sediment discharge) $[13,20]$.

2.2. Landslide Mapping. To understand the extent and duration of the impact of Typhoon Morakot, catchment-scale landslide inventories across Taiwan were interpreted using SPOT-4 satellite remote sensing images with a spatial resolution of $10 \mathrm{~m}$ in multispectral mode. Images with minimal cloud cover were selected from before and after the typhoon and heavy rainfall events. All images were orthorectified to a standard base image and checked manually using fixed visible markers to ensure spatial consistency over time. Given 


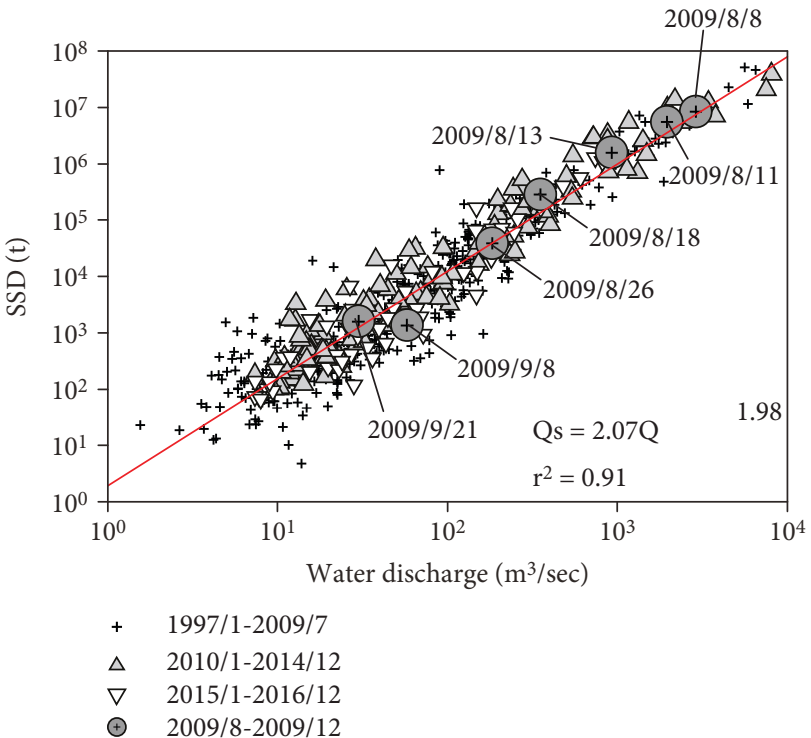

(a) Zhuoshui River (1510H057)

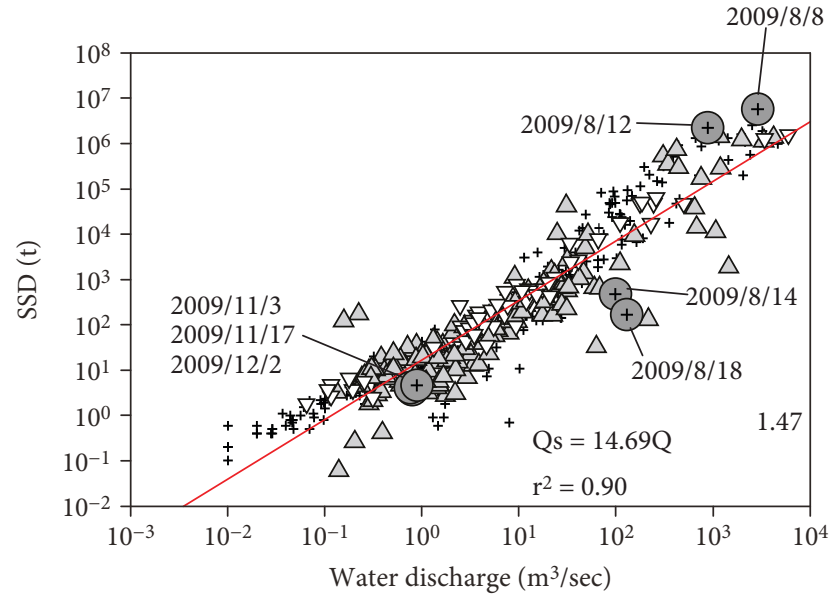

(b) Zengwen River (1630H019)

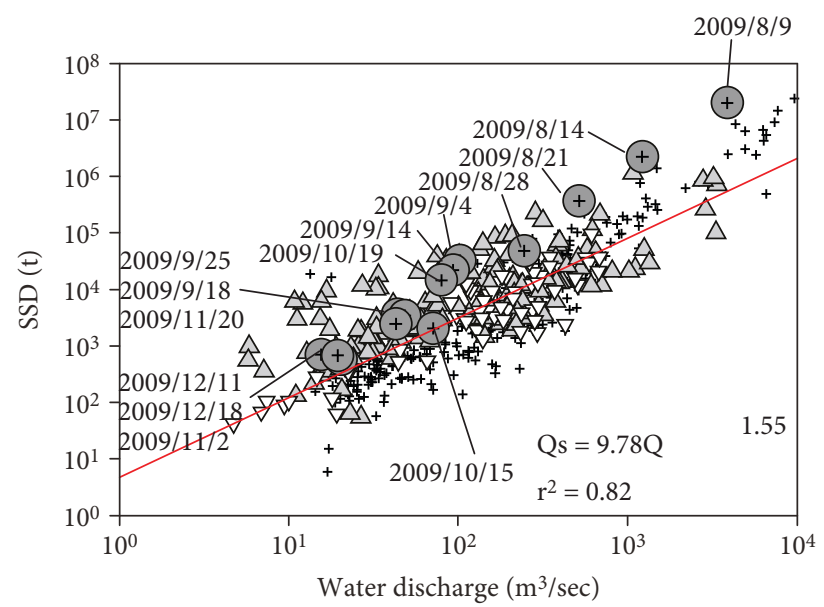

(c) Gaoping River (1730H043)

FIgURE 2: Relationship between suspended sediment discharge $\left(Q_{s}\right)$ and water discharge $(Q)$ for each river: (a) the Zhuoshui River, (b) the Zengwen River, and (c) the Gaoping River. The red lines represent the regression lines of all 1997-2016 data.

that a fully manual interpretation of landslides for wide catchments remains inefficient and impractical, the landslide mapping utilized an automated and preliminary interpretation procedure, which has been validated a priori against a subcatchment of the Zhuoshui River, rendering an accuracy of greater than $90 \%$. Presented herein is a brief description of the procedure to determine the landslide inventory maps to form the basis for the presented results.

The normalized difference vegetation index (NDVI) was adopted to conduct a preliminary and supervised classification of bare areas [21]. The exact NDVI thresholds for bare areas differed from one image to another and were determined by tuning the cutoff value based on visible contrasts. Subsequently, the classified areas were clustered based on slopes using a digital elevation model (DEM) with a resolution of $40 \mathrm{~m}$ to identify bare areas not associated with landslides (e.g., slope of the source area less than $10^{\circ}$ ). The interpretation procedure, facilitated by the NDVI thresholds and DEM-derived slope map, was implemented on the ArcGIS software for the automated interpretation. The interpretation results were carefully compared with an official 1:5000 topographic map to exclude areas of interpretation misjudgment (e.g., roads and buildings). Compared to a manual landslide identification using aerial photography, the accuracy of the automated interpretation (NDVI and DEM-derived slope map) showed to be greater than $90 \%$ (Figure S1). The annual landslide distribution map for each catchment is the result after the erasure of landslides that occurred in the previous year. In this study, the landslide ratios were also quantified to characterize landslides $[4,5]$. The landslide ratio is the ratio of the total landslide area to the total catchment area.

\section{Results}

3.1. Suspended Sediment Discharge before the 2009 Typhoon Morakot. The historical variations of SSD from the three 
considered rivers were gained by the modified rating curve method. In the period of 1997-2008, the cumulative SSD transported through the Zhuoshui River was $1152 \mathrm{Mt}$ and the cumulative water flux was $58.5 \times 10^{9} \mathrm{~m}^{3}$ (Figure 3(a)). The Zhuoshui River produced the largest amount of SSD among the three rivers. The average annual SSD before the 2009 Typhoon Morakot in the Zhuoshui River was 96.0 Mt/ $\mathrm{yr}$, and the average sediment yield in the unit catchment area was $33,035 \mathrm{t} / \mathrm{km}^{2} / \mathrm{yr}$.

As a result of the extreme Mw 7.3 earthquake of September 21,1999 , which significantly affected the mountainous areas of Taiwan, more than 10,000 landslides occurred. Some studies have reported that SSD obviously increases after a heavy earthquake [6, 22-24], and so accordingly, the 1999 earthquake can be used to divide the long-term average SSDs into pre- and postearthquake SSDs.

The average cumulative rate of SSD in unit water volume in the Zhuoshui River was $4.8 \times 10^{-3} \mathrm{t} / \mathrm{m}^{3}$ before 1999 and $51.2 \times 10^{-3} \mathrm{t} / \mathrm{m}^{3}$ in the period of $1999-2001$, which was the highest of the increased rate among the three rivers. The result indicates that the yield of sediment in the Zhuoshui River was obviously increased by the earthquake in 1999.

The Zengwen catchment is located a fair distance from the epicenter area of the 1999 earthquake and, consequently, the seismic waves weakened gradually. The annual SSD in the Zengwen River in the period of 1997-2008 ranged between 1.2 Mt/yr and $24.5 \mathrm{Mt} / \mathrm{yr}$, with an average of $7.9 \mathrm{Mt} / \mathrm{yr}$, and the average sediment yield in the unit catchment area per year was $8026 \mathrm{t} / \mathrm{km}^{2} / \mathrm{yr}$. In the period of $1997-2008$, the cumulative SSD transported through the Zengwen River was $95 \mathrm{Mt}$ and the cumulative water flux was $15.8 \times 10^{9} \mathrm{~m}^{3}$ (Figure 3(b)). Consequently, in the period of 1997-2008, the average cumulative rate of SSD in unit water volume in the Zengwen River was $3.8 \times 10^{-3} \mathrm{t} / \mathrm{m}^{3}$.

The average annual SSD in the Gaoping River in the period of 1997-2008 was $38.9 \mathrm{Mt} / \mathrm{yr}$, and the average sediment yield in the unit catchment area per year was 11,956t/ $\mathrm{km}^{2} / \mathrm{yr}$. The cumulative SSD transported through the river before 2009 was $266.3 \mathrm{Mt}$, and the cumulative water flux was $92 \times 10^{9} \mathrm{~m}^{3}$ (Figure $3(\mathrm{c})$ ). The average cumulative rate of SSD in unit water volume in the Gaoping River was $2.8 \times 10^{-3} \mathrm{t} / \mathrm{m}^{3}$.

3.2. SSD during Typhoon Morakot and the 2009 Annual Sediment Discharge. During Typhoon Morakot, the SSD of $136.5 \mathrm{Mt}$ was transported from the mountainous catchment of the Zhuoshui River, which comprised $91.4 \%$ of the annual SSD in 2009 and even reached $142.2 \%$ of the average annual SSD (Table 1). Furthermore, the cumulative rates of SSD in unit water volume of $42.7 \times 10^{-3} \mathrm{t} / \mathrm{m}^{3}$ in 2009 were 2.7 -fold higher than the average in the period of 2001-2008. In the southwestern region, the Zengwen River produced an SSD of 50.7 Mt during Typhoon Morakot; its SSD value reached $58.3 \%$ of the 2009 annual SSD. The cumulative rate of SSD in unit water volume reached $30.3 \times 10^{-3} \mathrm{t} / \mathrm{m}^{3}$.

In addition, during Typhoon Morakot, the Gaoping River produced SSDs of $570 \mathrm{Mt}$ (97.6\% of the 2009 annual SSD), which exceeded the average annual SSDs of the river by 15 -fold. Meanwhile, the 2009 cumulative rate of SSD in unit water volume in the river was $102.3 \times 10^{-3} \mathrm{t} / \mathrm{m}^{3}$. The 2009 cumulative rates of SSD in unit water volume increased 37 times. These facts strongly suggest that abundant sources of sediment significantly increase the SSD in rivers after a heavy typhoon.

The calculation of the 2009 annual SSDs showed that the Gaoping River produced the maximum annual SSD of 584.2 Mt, followed by the Zhuoshui River, with 149.3 Mt. The amount of sediment brought to the rivers due to huge mass movements on slopes after the typhoon raised the 2009 annual SSD to 15 times higher than the past annual averages.

\subsection{Catchment-Scale Variations of Landslides. Considering} the differences in the catchment area between the three rivers, the influence of Typhoon Morakot on the different catchments is presented in terms of landslide ratio. The landslide ratio induced by Typhoon Morakot in the Zhuoshui River was not significantly higher than that in the past, and the ratios descended quickly after 2009 (Figure 4). The typhoon caused the largest scale mass movements in the Zengwen and Gaoping Rivers in the past decades. It is clear that landslide ratios in the three catchments were associated with differential impact levels.

The variation in the number of landslides during 20052016 in the Zengwen catchment is almost consistent with the changes in landslide ratios (Figure 5(a)). In the past 12 years, these results have indicated that the main types and sizes of mass movements in the Zengwen catchment changed within a narrow range, and it is clear that Typhoon Morakot was the rainstorm event that caused the most landslides. By comparing the amount of cumulative rainfall and landslide numbers during 2005-2008, we found that the number of landslides rose with increasing cumulative rainfall, but this state was changed after the typhoon. The extreme cumulative rainfall during the typhoons caused an abrupt increase in the number of landslides. After Typhoon Morakot, the intensity of rainfall brought by typhoons in the period of 2010-2014 was relatively moderate, but the number of landslides was not significantly reduced. Therefore, before and after Typhoon Morakot, the relationship between cumulative rainfall and landslide number seems to have exhibited different trends (Figure 5(b)). It is noteworthy that, in 2015 and 2016, the relationship between cumulative rainfall caused by typhoons and the number of landslides appeared to have returned to the state prior to Typhoon Morakot.

\section{Discussion}

The changes in observations of SSD reflected the impact of Typhoon Morakot on the annual SSD from the rivers in central and southwestern Taiwan. The extreme rainstorms during the typhoon not only induced a great deal of event-induced SSD but also affected the amount of SSD. The influences of Typhoon Morakot on sediment yields in each catchment were obviously different. The suspended sediment discharge measured in the period from August 7 to December 31 in 2009 was compared with all SSD data 


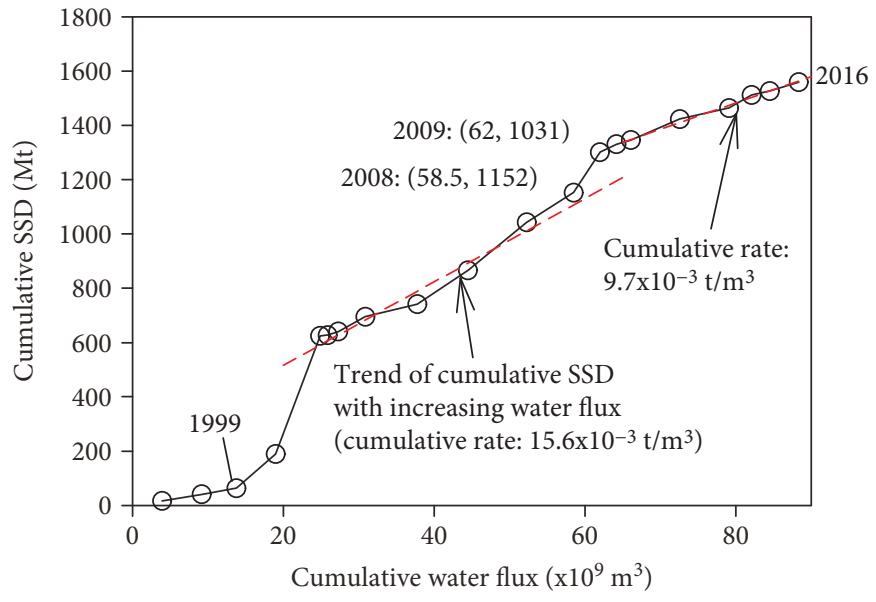

(a) Zhuoshui River (1510H057)

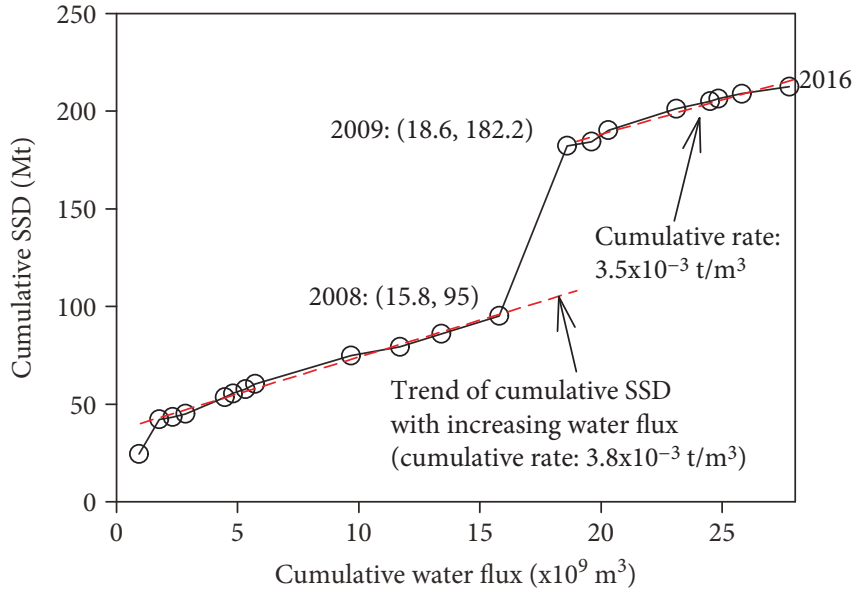

(b) Zengwen River (1630H019)

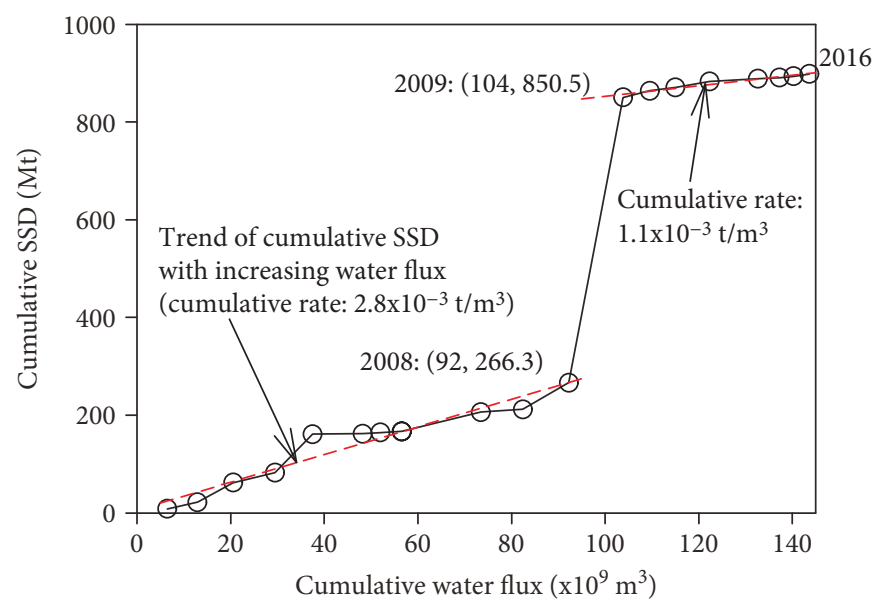

(c) Gaoping River (1730H043)

Figure 3: Cumulative water flux and SSD in (a) the Zhuoshui River, (b) the Zengwen River, and (c) the Gaoping River in the period from 1997 to 2016 .

TABLE 1: Statistics of SSD in the three catchments.

\begin{tabular}{lcccccc}
\hline Catchment & Area $\left(\mathrm{km}^{2}\right)$ & $\begin{array}{c}\text { SSD during Typhoon } \\
\text { Mindulle (Mt) }\end{array}$ & 2009 SSD (Mt) & $\begin{array}{c}\text { Proportion of typhoon } \\
\text { SSD to 2009 SSD (\%) }\end{array}$ & $\begin{array}{c}\text { 1997-2008 average } \\
\text { annual SSD (Mt) }\end{array}$ & $\begin{array}{c}\text { 2010-2015 average } \\
\text { annual SSD (Mt) }\end{array}$ \\
\hline Zhuoshui River & 2906 & 136.5 & 149.3 & 91.4 & $96.0 \pm 34.8$ & $37.5 \pm 9.6$ \\
Zengwen River & 988 & 50.7 & 87.0 & 58.3 & $7.9 \pm 2.1$ & $4.4 \pm 1.5$ \\
Gaoping River & 3257 & 570.0 & 584.2 & 97.6 & $38.9 \pm 16.3$ & $7.2 \pm 2.0$ \\
\hline
\end{tabular}

(Figure 2). The SSD in the Gaoping River increased most significantly. The comparison of the relationship between SSD and water discharge after the Typhoon Morakot with the relationship before the typhoon presents a different variation mode in the Zengwen River and Gaoping River. In contrast to the fact that the amount of SSD delivered from the Gaoping River increased significantly after the typhoon, the SSD greater than the historical mean in the Zengwen River was observed only when water discharge was greater than $100 \mathrm{~m}^{3} / \mathrm{sec}$, and even measured SSD was greater than the historical maximum at the same water discharge. The maximum cumulative rainfall during Typhoon Morakot in the southwestern region exceeded $1500 \mathrm{~mm}$; however, the maximum cumulative rainfall in the central region did not exceed $1500 \mathrm{~mm}$ (Figure 1), indicating that the cumulative rainfall decreased northward. The difference between the SSD after the Typhoon Morakot and historical data of the Zhuoshui River was insignificant, and this is explained by the fact that the influence of the typhoon gradually decreased northward.

The $\kappa$ value of the $Q_{s}-Q$ rating curve, corresponding to the twenty-year data collected from the Zengwen River, is larger than that of the Zhuoshui River and the Gaoping River (Figure 2). A large part of the Zengwen River catchment is 


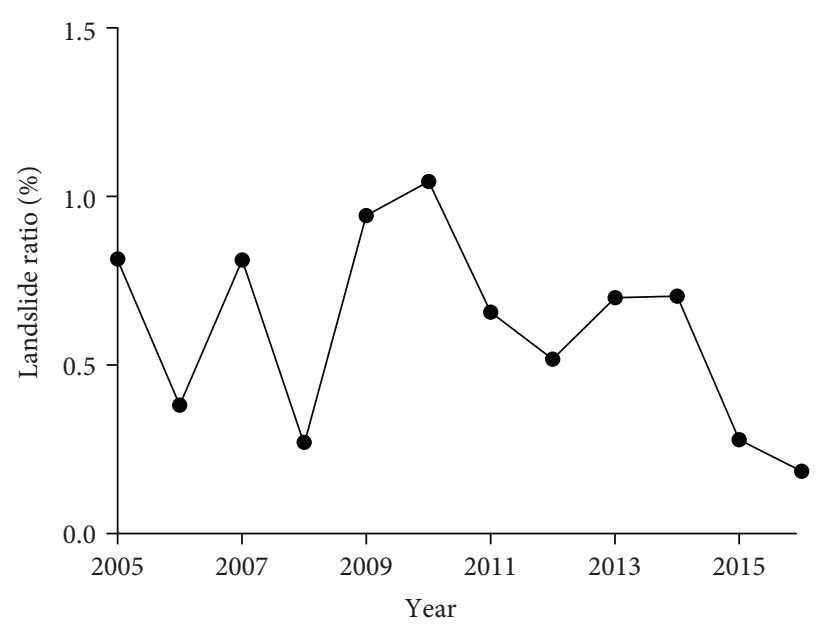

(a) Zhuoshui River

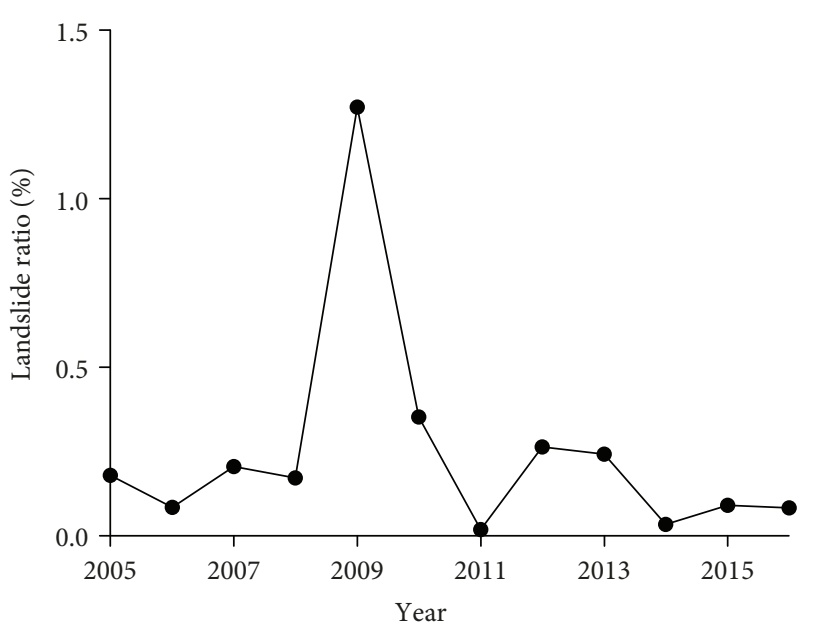

(b) Zengwen River

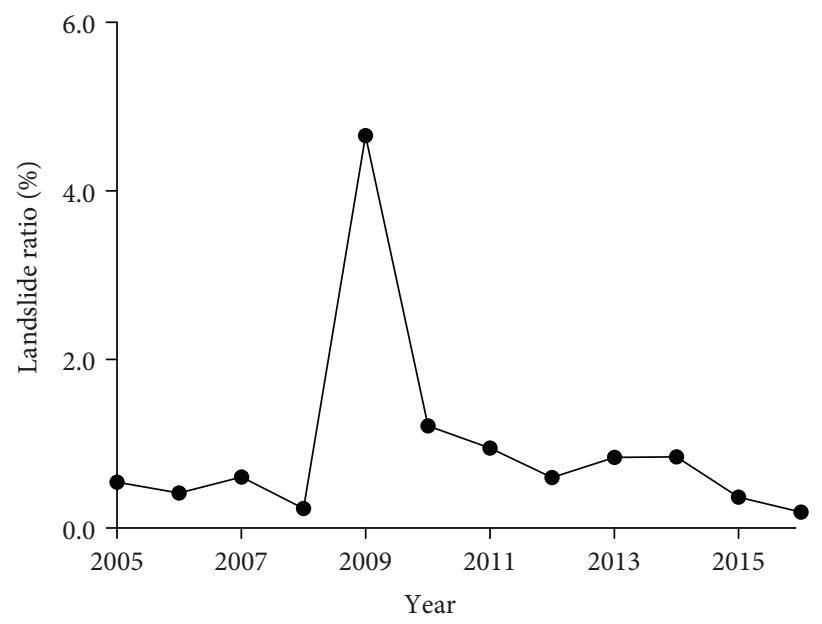

(c) Gaoping River

FIgURE 4: The variations of landslide ratios in the three catchments during 2005-2016.

occupied of young and poorly cemented mudstones [25-27]. The natural characteristics of the mudstones are sensitive to weathering and prone to rainfall-induced erosions, bringing abundant fine-grained sediments and relatively greater yielding rates of the SSD $[28,29]$. The fine-grained sediments stemming from the mudstones also explained the milder decrements in the cumulative rate of the SSD in the Zengwen River (Figure 3). When water discharge was less than $100 \mathrm{~m}^{3} / \mathrm{sec}$, the observed SSDs in the following four months (September to December) after the typhoon had unobvious difference from that SSDs observed prior to the typhoon. In addition, a huge amount of fine-grained sediment would be delivered downstream during the typhoon as well as the subsequent months, alleviating the cumulative rates of the SSD in the following years after the Typhoon Morakot. The variations of the cumulative rates of the SSD during 1997-2016 signify that the impact of an extreme rainstorm on fluvial fine-grain sediment could be violent; nevertheless, such impact may last for only a few months.

Although the landslide ratios appear to have rapidly declined after 2010, it should be noted that Taiwan's mountainous areas had relatively dry climatic conditions during
2010-2014. It is noteworthy that, in 2015 and 2016, the relationship between cumulative rainfall caused by typhoons and the number of landslides in the Zengwen River catchment appeared to have returned to the state prior to Typhoon Morakot. In terms of the changes in relationships between landslide and rainfall, a similar trait was established in catchments of the Gaoping and Zengwen Rivers, both showing that the influence of the typhoon could linger for 4-5 years; however, such trait could not be observed in the Zhuoshui River catchment (Figure 5). According to the results, the influence of the typhoon on landslides and SSD was quite different, in which, the former and the latter lasted $4-5$ years and 4 months, respectively. The relatively longer recovery period on landslides could be attributed to the gradual process of landslide materials developing into fine-grained sediments, eventually becoming the sources of SSD.

The slight difference in landslide ratios for the relatively drier periods during 2010-2014 pointed out that rainfall conditions for triggering landslides could have changed after Typhoon Morakot. The Soil and Water Conservation Bureau of Taiwan investigated more than 321 landslides 


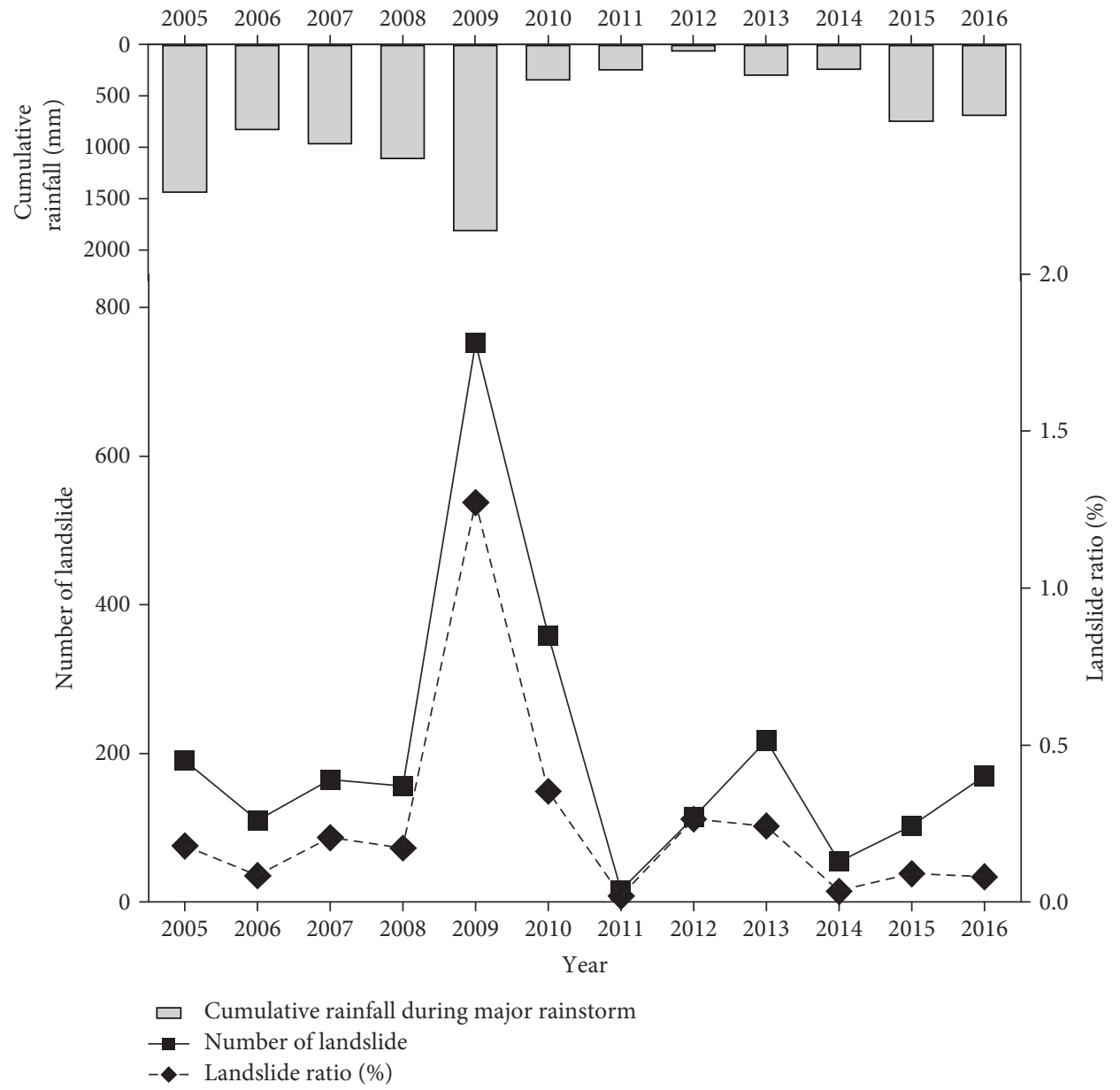

(a) Zengwen

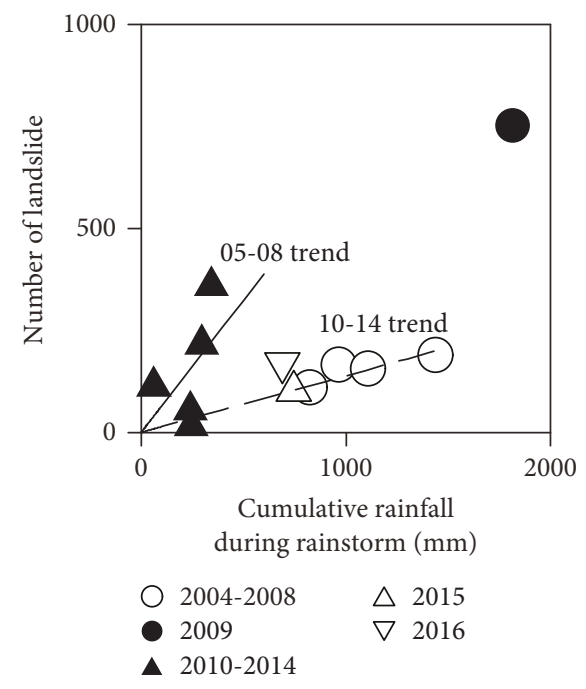

(b) Zengwen

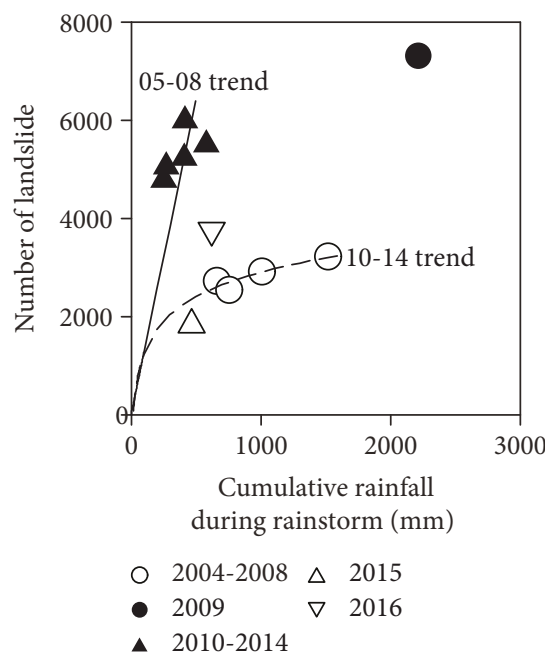

(c) Gaoping

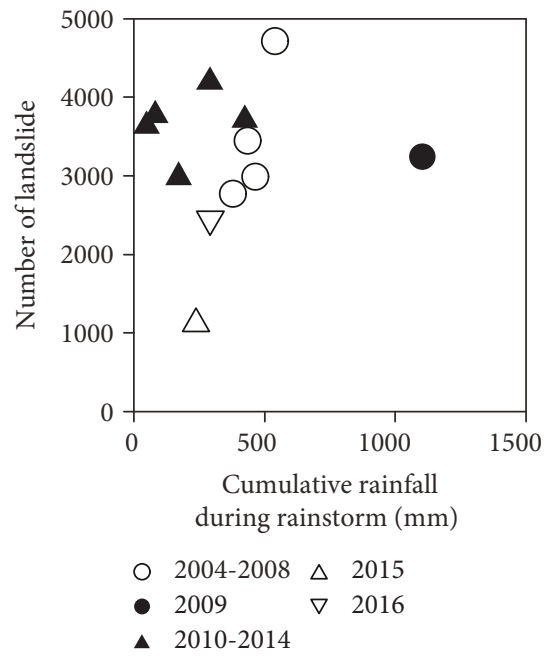

(d) Zhuoshui

Figure 5: (a) The variations of landslides during 2005-2016 in the Zengwen River catchment. (b-d) The relationships between the landslide number and cumulative rainfall in the Zengwen River, Gaoping River, and Zhuoshui River catchments.

that occurred in Taiwan during 2006-2014 and collected rainfall data for the areas where they occurred. The numbers of investigated landslides in the southern region barring 2009 data (outlier) were 35 during 2006-2008 and 23 during 2010-2014. The critical rainfall condition for landslides was estimated by the rainfall intensity-duration (I-D) threshold 


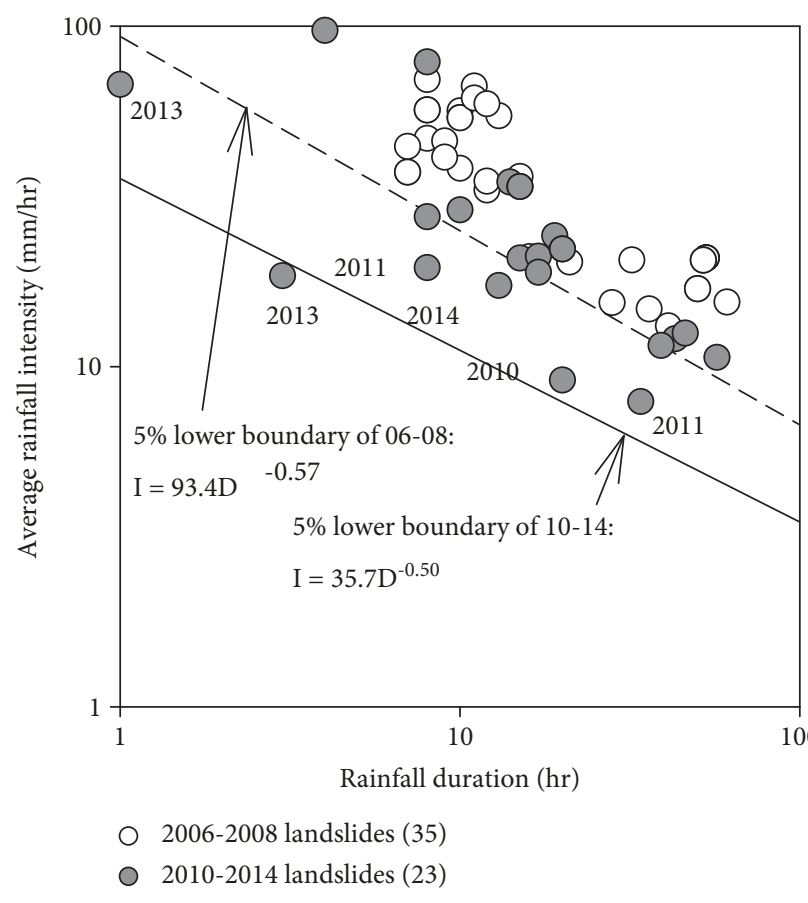

(a) Southern region

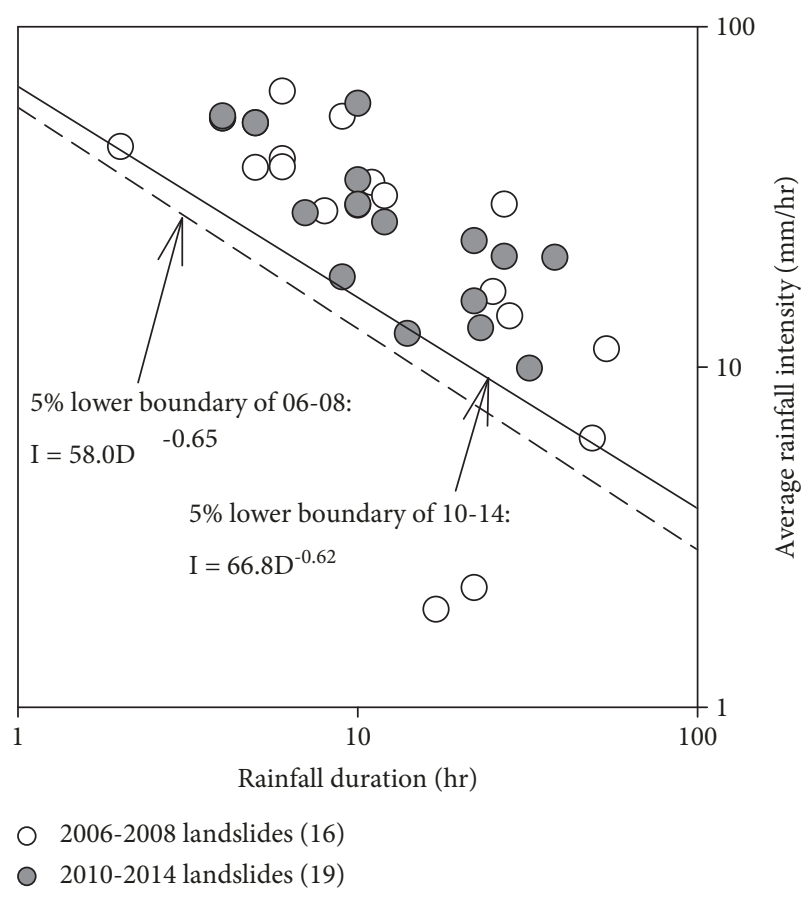

(b) Northern region

FIGURE 6: The lower boundaries of rainfall condition for triggering landslides in 2006-2008 and 2010-2014. (a) 58 landslides in the southern region. The numbers labeled around the data lower than the lower boundary of 06-08 mean the occurrence year of event. (b) 35 landslides in the northern region.

using the frequentist method proposed by Brunetti et al. [30]. In that study, the critical line was defined as the threshold corresponding to the $5 \%$ exceedance probability. Obviously, the 2010-2014 critical line was lower than the 2006-2008 line (Figure 6(a)), indicating that the critical rainfall for initiating landslides in the southern region dropped after Typhoon Morakot. In contrast, the change in the rainfall conditions for triggering landslides in the northern region was rather slight after the typhoon (Figure 6(b)). Furthermore, on a long-term basis, to explore the gradual restoration of the threshold after an extreme typhoon and expound the role of such event in subsequent sediment discharges and rainfall-driven landslides, it is suggested that future observations on the effects of Typhoon Morakot be continued.

\section{Conclusions}

The maximum cumulative rainfall caused by Typhoon Morakot in 2009 exceeded $1500 \mathrm{~mm}$, leading to catastrophic slope failures and flooding disasters in the central and southwestern regions of Taiwan, as well as large amounts of suspended sediment discharges (SSDs). In this study, the SSDs in the three major rivers in Taiwan, the Zhuoshui River, the Zengwen River, and the Gaoping River, were estimated from the measured data of water discharge and sediment concentration. The estimation of the SSD from each river showed that the sediment yields during Typhoon Morakot comprised at least $58 \%$ of the 2009 annual SSD, and the SSD in the
Gaoping River during the typhoon reached $98 \%$ of the annual SSD. In addition, during Typhoon Morakot, the total amount of SSD in the catchments in the southwestern region of Taiwan exceeded the average annual sediment discharge for the years before 2008. This finding is a clear indication that the amount of SSD of a single rainstorm can be higher than the average annual SSD. The amount of the 2009 annual SSD in each river was attributed to an extreme event and can lead to SSD 15 times higher than the corresponding average annual SSD. These results indicate that the sediment supply in these catchments was greatly affected by the extreme rainfall during Typhoon Morakot, creating an unusually large sediment discharge for the year. By comparing the SSDs affected by Typhoon Morakot in the three rivers, we found that the Gaoping River was affected most significantly, but the influence gradually decreased northward. The impact of the typhoon on suspended sediment discharge lasted for around four months. The variations of landslide ratios in these three catchments revealed that Typhoon Morakot caused the largest-scale mass movement disaster in the southwestern region of Taiwan in the past decades. The relationship between the landslide number and rainfall in the Zengwen River and Gaoping River catchments during 2005-2016 revealed that the impact of an extreme typhoon on landslides in a given basin could last for 4-5 years. Furthermore, the comparison of the rainfall thresholds before and after the typhoon indicated that the critical rainfall for triggering landslides declined during the years following the extreme event. 


\section{Data Availability}

The data used to support the findings of this study are available from the corresponding author upon request.

\section{Conflicts of Interest}

The authors declare that they have no conflicts of interest.

\section{Acknowledgments}

This work was supported by the Ministry of Science and Technology in Taiwan. We thank the officials and crews of the Water Resources Agency, Ministry of Economic Affairs of Taiwan, for supplying the hydrometric data.

\section{Supplementary Materials}

The supplementary material includes one supplementary figure (Figure S1) and three supplementary tables (Tables S1 S3). Figure S1: the comparison of landslide inventory maps of manual and automated identification. Tables S1, S2, and S3: the yearly rating curves and observation days of SSD and water discharge in the Zhuoshui River, Zengwen River, and Gaoping River, respectively. (Supplementary Materials)

\section{References}

[1] S. L. Shieh, Users' Guide for Typhoon Forecasting in the Taiwan Area (VIII), Central Weather Bureau, Taipei, 2000.

[2] Y. C. Chen, K. T. Chang, Y. J. Chiu, S. M. Lau, and H. Y. Lee, "Quantifying rainfall controls on catchment-scale landslide erosion in Taiwan," Earth Surface Processes and Landforms, vol. 38, no. 4, pp. 372-382, 2013.

[3] C. W. Chen, T. Oguchi, Y. S. Hayakawa et al., "Sediment yield during typhoon events in relation to landslides, rainfall, and catchment areas in Taiwan," Geomorphology, vol. 303, pp. 540-548, 2018.

[4] G. W. Lin, H. Chen, Y. H. Chen, and M. J. Horng, "Influence of typhoons and earthquakes on rainfall-induced landslides and suspended sediments discharge," Engineering Geology, vol. 97, no. 1-2, pp. 32-41, 2008.

[5] S. C. Chuang, H. Chen, G. W. Lin, C. W. Lin, and C. P. Chang, "Increase in basin sediment yield from landslides in storms following major seismic disturbance," Engineering Geology, vol. 103, no. 1-2, pp. 59-65, 2009.

[6] S. J. Dadson, N. Hovius, H. Chen et al., "Links between erosion, runoff variability and seismicity in the Taiwan orogen," Nature, vol. 426, no. 6967, pp. 648-651, 2003.

[7] A. C. Gellis, "Factors influencing storm-generated suspendedsediment concentrations and loads in four basins of contrasting land use, humid-tropical Puerto Rico," Catena, vol. 104, pp. 39-57, 2013.

[8] T. Y. Lee, J. C. Huang, J. Y. Lee, S. H. Jien, F. Zehetner, and S. J. Kao, "Magnified sediment export of small mountainous rivers in Taiwan: chain reactions from increased rainfall intensity under global warming," PLoS One, vol. 10, no. 9, article e0138283, 2015.

[9] G. W. Lin, H. Chen, D. N. Petley, M. J. Horng, S. J. Wu, and B. Chuang, "Impact of rainstorm-triggered landslides on high turbidity in a mountain reservoir," Engineering Geology, vol. 117, no. 1-2, pp. 97-103, 2011.

[10] Y. M. Wang, S. S. Tfwala, H. C. Chan, and Y. C. Lin, "The effects of sporadic torrential rainfall events on suspended sediments," Archives of Sciences, vol. 66, pp. 211-224, 2013.

[11] CWB, Climatological Data Annual Report, Central Weather Bureau, Taipei, Taiwan, 2009.

[12] J. C. Chen and M. R. Chuang, "Discharge of landslide-induced debris flows: case studies of Typhoon Morakot in southern Taiwan," Natural Hazards and Earth System Sciences, vol. 14, no. 7, pp. 1719-1730, 2014.

[13] WRA, "Hydrological yearbook of Taiwan," in Water Resources Agency, Ministry of Economic Affairs, Taiwan, 2015.

[14] K. H. Ahn and S. Steinschneider, "Time-varying suspended sediment-discharge rating curves to estimate climate impacts on fluvial sediment transport," Hydrological Processes, vol. 32, no. 1, pp. 102-117, 2018.

[15] Z. A. Boukhrissa, K. Khanchoul, Y. Le Bissonnais, and M. Tourki, "Prediction of sediment load by sediment rating curve and neural network (ANN) in El Kebir catchment, Algeria," Journal of Earth System Science, vol. 122, no. 5, pp. 1303-1312, 2013.

[16] T. A. Cohn, "Recent advances in statistical methods for the estimation of sediment and nutrient transport in rivers," Reviews of Geophysics, vol. 33, no. S2, pp. 1117-1123, 1995.

[17] S. J. Kao, S. C. Chan, C. H. Kuo, and K. K. Liu, "Transportdominated sediment loading in Taiwanese rivers: a case study from the Ma-an Stream," The Journal of Geology, vol. 113, no. 2, pp. 217-225, 2005.

[18] S. Tfwala and Y.-M. Wang, "Estimating sediment discharge using sediment rating curves and artificial neural networks in the Shiwen River, Taiwan," Water, vol. 8, no. 2, 2016.

[19] N. Hovius, C. P. Stark, C. Hao-Tsu, and L. Jiun-Chuan, "Supply and removal of sediment in a landslide-dominated mountain belt: Central Range, Taiwan," The Journal of Geology, vol. 108, no. 1, pp. 73-89, 2000.

[20] J. Xu, "Trends in suspended sediment grain size in the upper Yangtze River and its tributaries, as influenced by human activities," Hydrological Sciences Journal, vol. 52, no. 4, pp. 777-792, 2007.

[21] C. W. Lin, C. L. Shieh, B. D. Yuan, Y. C. Shieh, S. H. Liu, and S. Y. Lee, "Impact of Chi-Chi earthquake on the occurrence of landslides and debris flows: example from the Chenyulan River watershed, Nantou, Taiwan," Engineering Geology, vol. 71, no. 1-2, pp. 49-61, 2004.

[22] H. Ding, Y. Li, S. Ni et al., "Increased sediment discharge driven by heavy rainfall after Wenchuan earthquake: a case study in the upper reaches of the Min River, Sichuan, China," Quaternary International, vol. 333, pp. 122-129, 2014.

[23] N. Hovius, P. Meunier, C. W. Lin et al., "Prolonged seismically induced erosion and the mass balance of a large earthquake," Earth and Planetary Science Letters, vol. 304, no. 3-4, pp. 347-355, 2011.

[24] M. Vanmaercke, A. J. Kettner, M. Van Den Eeckhaut et al., "Moderate seismic activity affects contemporary sediment yields," Progress in Physical Geography, vol. 38, no. 2, pp. 145-172, 2014.

[25] H. W. Chang, Y. M. Tien, and C. H. Juang, "Formation of south-facing bald mudstone slopes in southwestern Taiwan," Engineering Geology, vol. 42, no. 1, pp. 37-49, 1996. 
[26] C. S. Ho, An Introduction to the Geology of Taiwan Explanatory Text of the Geologic Map of Taiwan, Central Geological Survey, Taipei, 1994.

[27] D. H. Lee, K. G. Tien, and C. H. Juang, "Full-scale field experimentation of a new technique for protecting mudstone slopes, Taiwan," Engineering Geology, vol. 42, no. 1, pp. 51-63, 1996.

[28] D. H. Lee, C. S. Tsai, and C. T. Weng, "A study on the failure behaviors of mudstones and the stabilization measures," in Disaster Prevention Investigation, National Science Council of Taiwan, Taipei, Taiwan, 1984.

[29] D. H. Lee and Y. M. Tien, "Fundamental engineering behaviors of mudstone," Sino-Geotechnics, vol. 19, pp. 26-34, 1985.

[30] M. T. Brunetti, S. Peruccacci, M. Rossi, S. Luciani, D. Valigi, and F. Guzzetti, "Rainfall thresholds for the possible occurrence of landslides in Italy," Natural Hazards and Earth System Sciences, vol. 10, no. 3, pp. 447-458, 2010. 

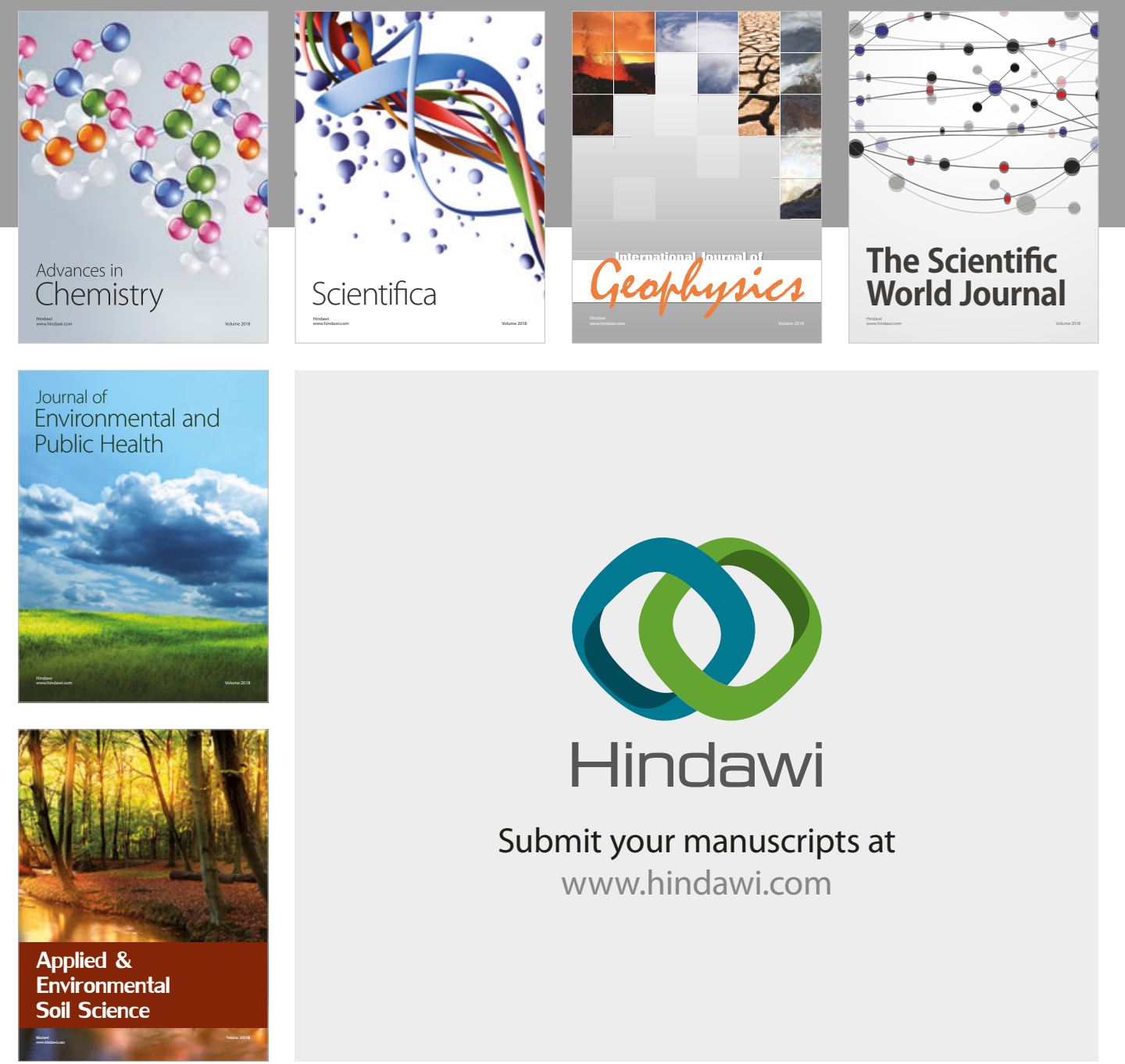

The Scientific

\section{World Journal}
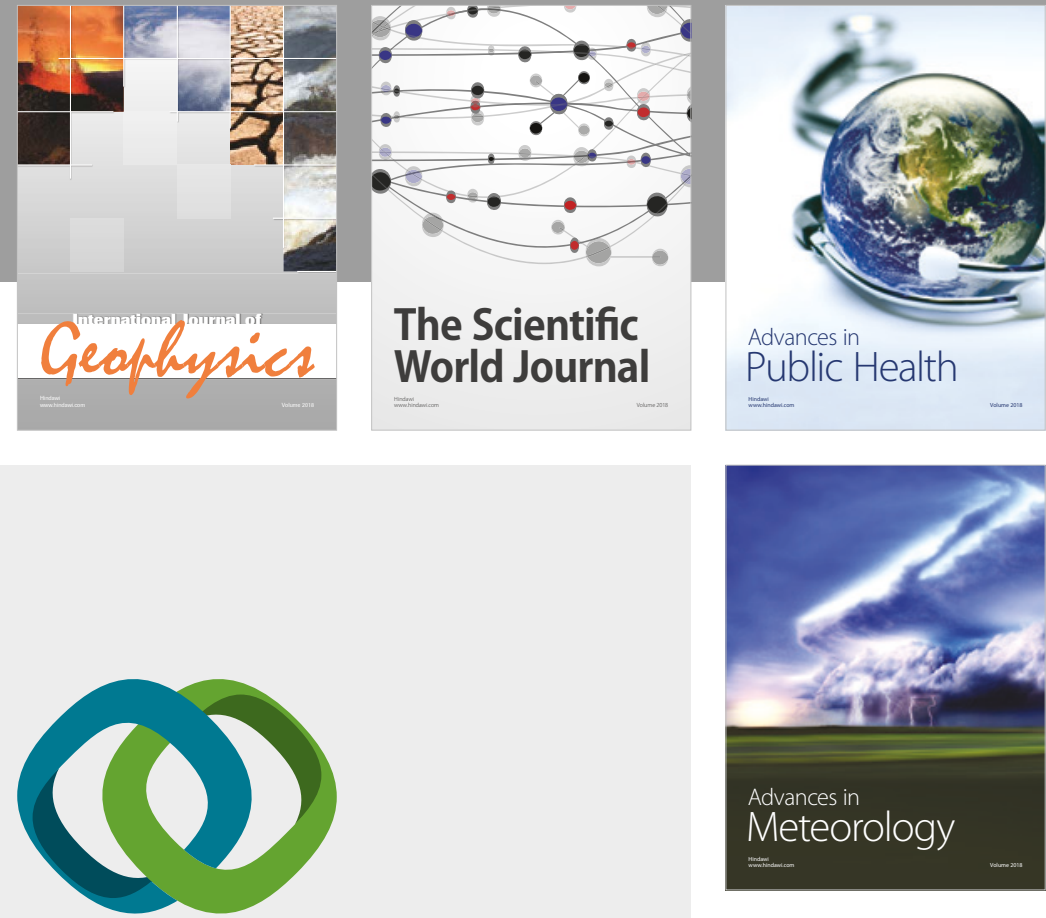

Advan

Public Health

\section{Hindawi}

Submit your manuscripts at

www.hindawi.com
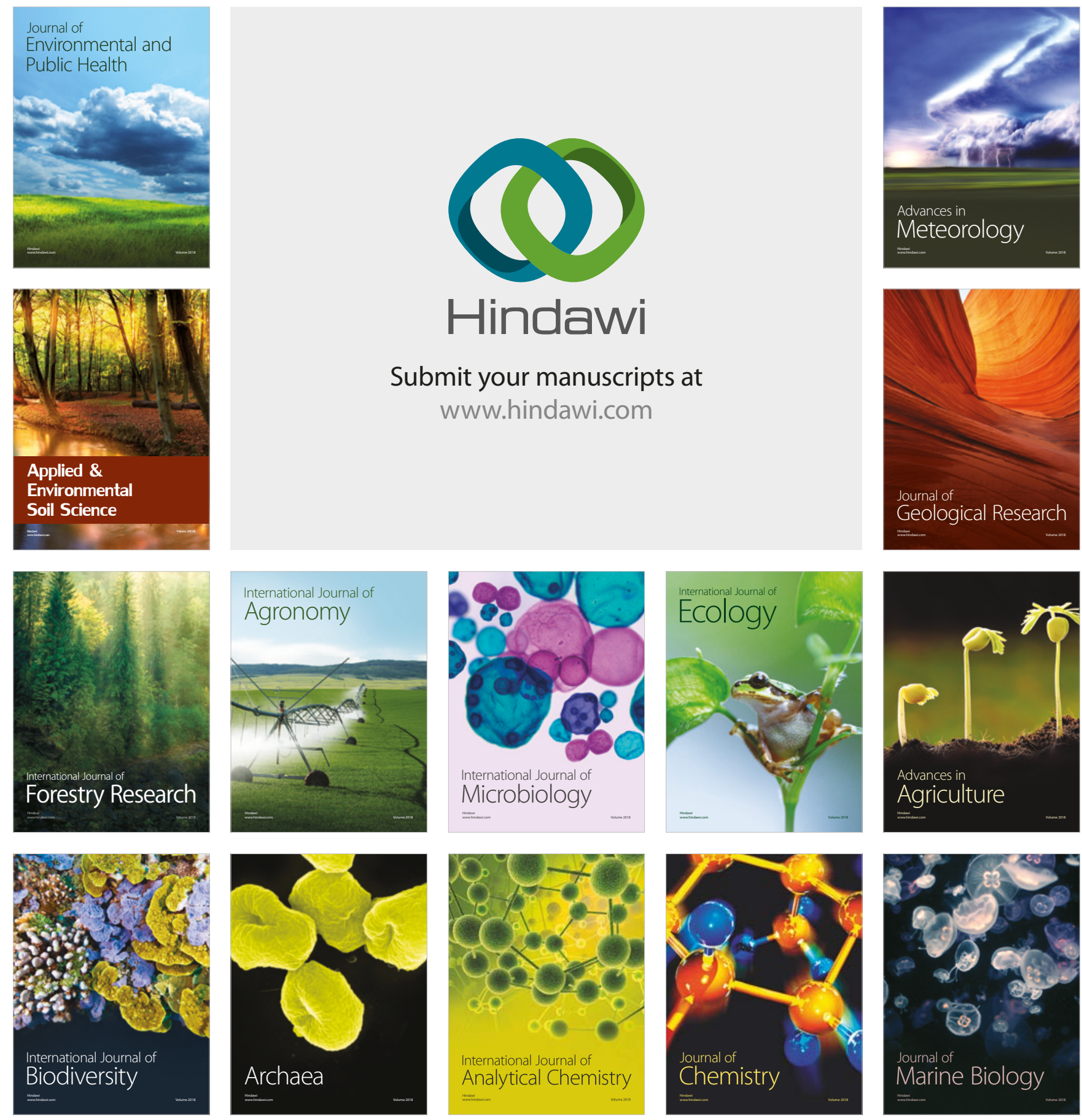